\title{
Towards Rumors Detection Framework for Social Media
}

\author{
Hadeer Sanaa \\ Faculty of Graduate Studies for \\ Statistical Research \\ Cairo University \\ Giza, Egypt
}

\author{
Nagy Ramadan \\ Faculty of Graduate Studies for \\ Statistical Research \\ Cairo University \\ Giza, Egypt
}

\author{
Hesham A. Hefny \\ Faculty of Graduate Studies for \\ Statistical Research \\ Cairo University \\ Giza, Egypt
}

\begin{abstract}
A Rumor is considered as unverified pieces of information circulating, that arise in the context of uncertainty, with negative impact, and falsely attributes. Unfortunately, terribly damaging form of communication are the results of rumors. Rumors spread on social media with no exception, and only serve to amplify the negative effects on people and businesses. This paper aims to present literature related to rumor detection on social network and try to find a link on how human behavior is affected by it. Therefore, it surveys the rumors detection frameworks, algorithms, and computational techniques that help in detecting and blocking rumors from spreading on social media. Also, attributes that may identify and describe a rumor and human behavior towards rumors are gathered, unified, and arranged in an integrated recommended list. This list of attributes may be the guide for detecting and capturing rumors with their changeable inconstant form. As a result, from this trial a proposed framework is presented to offer an idea for dealing with human behavior on rumors. This model presents open issues and forwarded ideas to provide an insight for future work in the area of building Rumor-Human Behavior computational models.
\end{abstract}

\section{General Terms}

Pattern Recognition, Machine learning, Social media computation.

\section{Keywords}

Rumors; Rumors attributes; Human Behavior; Social media rumors

\section{INTRODUCTION}

Rumors are defined as unverified and instrumentally relevant information statements in circulation that arise in the context of ambiguity, danger or potential threat, and that function to help people make sense and manage risk [1]. The spreading of unsubstantiated rumors, whether intentional or unintentional, could have serious consequences; the World Economic Forum has listed massive digital. Many researchers argued that rumors can cause a lot of crises [2,3, and 4]. Therefore, rumor could not only be a diffusion process of information, but also a process of explanation and comment. This process is characterized by anonymity, timeliness, bursting, repeatability, and irritation.

On the other hand, every time user socializes on social networks, a lot of information is left behind. This information is a good indicator on their attitude that could describe their behavior and relationship [5]. This information could be collected and analyzed to enable exploring crowed behavior and human interactions rather than using the traditional survey-based methodology or the traditional simulation base methodology. From this side; human behavior analysis, trend is born as it is the quantifying of human movements, interactions and behaves. Studying people interaction shows behavior between them in different status such as: the places of works, lives, eat, hang out [1], obesity levels, reproductive fitness, health characteristics [6], political affiliations [7], college choices, usage behavior, happiness and emotions [8], propaganda level and rumors [9] and so one.

However, it was found that almost all recent works in rumors have a shortage in dealing with rumor phenomenon on social media; rumors nature yields certain requirements for handling them. Firstly, rumors vary accordingly with their content, type, nature and orientation. This means that rumors never have constant form or category. Secondly, as time passes different techniques for handling rumors changes with the evolution of rumor natures which may not be applicable for next rumors. Finally, the prediction of crowd behavior upon these rumors is a complex and challenged process but, it is highly demanded, since many unexpected, different and dependent events may occur, i.e. rumors may influence general opinion or affect marketing issues.

In this research, a survey is presented on literatures studied of rumors and human behavior detection methods. Algorithms, methods, and computational techniques are studied stating a proposed advantages and disadvantages for each. Then a proposed model is presented so that it may enhance some of the proposed disadvantages. Also integrating human behavior in research is useful as it may help for finding link towards computing human behavior towards rumors. Studying human behavior on rumors is big issue need to be considered for better understanding rumors effects and predict these effects on the environment.

This paper is organized into four main sections, section 2 presents general background on rumors definitions, rumors and social media, types of rumors, and rumors effects on human behavior. Followed by section 3 that introduces the related. Then section 4 that presents the proposed framework that gives an idea for enhancing the proposed disadvantages found in related works. Finally, the section 5 conclusions are exposed.

\section{BACKGROUND}

Rumors have many forms, phases, identification phases, and techniques for studying on social media. Generally, there are many aspects for measuring and dealing with rumors. In this section a trial of general definition and explanations is presented to give a general overview of rumors.

\subsection{Rumors and Social Media:}

Any unverified type of claim about any event, sent from one person to another over social media are considered to be a rumor. It could appear after an incident, or problem of public concern. In [10], the authors defined rumor as a story or 
statement in general circulation without confirmation or certainty to facts. While in [11], a story or a statement whose truth value is unverified or deliberately false is considered as rumor.

Social media has the power to make any information, whether being it true or false, to go viral, reaching and affecting millions. Nowadays, the discovery of social network services has led the public to spread rumors at the fastest rate. For that, social media are considered to be rapid in transferring unverified statements that could be dangerous for human and affect his behavior [12].

\subsection{Effect of Rumors on Human Behavior}

Generally, rumors could influence badly on human behavior causing troubles and dangers for people. Rumors could affect psychological stages of people [11] in which it makes them act in harmful ways, therefore it so important to take this into consideration. Usually, some rumors are used for monitoring public opinions and events on social media events [13]. These events could be gossips of political views or a campaign strategy to slander political opponents [14] that would attract people to transmit lies rather than search for the truth. Therefore, rumors play important role in affecting the psychological states and attitude of the crowd. Also, sometimes subjective rumors are created systematically so that it can capture information about users' behavior, actions, opinion and predict their reactions.

\section{RELATED WORKS}

An intensive survey on related and recent works has been done in many aspects of rumors and human behavior on social media for capturing methods and techniques to be measured. Finally, advantages and disadvantages are mentioned with a discussion on proposed ideas and purposes.

In [15], the authors perform questionnaire gathering information to discuss the reasons behind the spreading of misinformation. They depend on Uses and Gratifications theory from literature to build the questionnaire for students in Singapore University with respect to taking varies in Gender and ages for testing. The study found that the reasons behind are the ability to spark conversations, self-expression and socializing motivations. Finally, they concluded that women are reported as a higher prevalence of sharing misinformation.

Studies $[16,17]$ are extendable as the authors discovered the credibility behind words and phrases which indicate whether an event is highly trusted or less. A corpus called CREDBANK adapted which were created from a large dataset of 1,377 social media varied event distributed over 66 million twitter messages with their credibility level of crowd sourced annotation. Then they built a statistical model (regression technique) to predict perceived credibility from language using CREDBANK to merge the linguistically knowledge data. The linguistic strategies used are corresponding to credibility assessment that were built on lexical and computational insights by using predictors from the language indicates perceived credibility level such as Modality (individual attitude), Subjectivity, Evidentially (reliability of reported information), negation, anxiety, positive and negative emotions ... The CREDBANK corpus was detailed explained in [16].

In [18], the authors relaying on the idea of finding signature text phrases used to express skepticism in claims by few peoples whom rarely express anything else. As this could be an indicator of rumor existence or recasting the problem by searching for entire clusters in topics have disputed posts.
This method uses the enquiry behavior of users on social media sensors as its clusters and extract only tweets statement that contain enquiry patterns (the signal tweets). Then they defined set of signal tweets using a definite set of regular expressions with identified features of signal clusters that can be used to effectively rank the clusters by their likelihood of containing a disputed factual claim.

In [19], the authors presented an Analysis and Early Detection of Rumors in a Post Disaster Scenario. They work on Identification of rumor tweets at early stage in the aftermath of a disaster is the focus of their work. They found that their rumor detection technique is able to find out rumors at early stages, even before contradicting or interrogating posts are posted. They plan to evaluate the performance of their proposed model for other types of disaster scenarios.

In [20], the authors explore if spreading rumors of user decision- making process on social media help in early detecting rumors. They analyze what factors could stimulate most in detecting and debunking the truthfulness of rumors. They proposed intensive detailed features including psychology theories for efficient results. They studied the level of rumor truth according to the responds of every user and why they spread rumors psychologically. Also, they introduced a new Reddit rumor dataset with a new truth level as rumors arranged in five categories: "False", "Mostly False", "True", "Mostly True", and "Half True". Then they proved that the proposed approach can detect the truthfulness of rumors efficiently.

In [21], the authors introduced a research on Arabic news credibility on twitter through enhanced model using hybrid features. A data set of 800 Arabic news that are manually labeled is collected from Twitter. Three different classification techniques were applied (Decision tree, support vector machine (SVM) and Naive Bayesian (NB). For model training and testing, 5-fold cross validations were performed and performance diagnostics were calculated. Results indicate that decision tree achieves TRP higher than SVM by around $2 \%$ and $7 \%$ than NB, also FPR almost $9 \%$ lower than SVM and $10 \%$ lower than NB.

In [22], the authors provided taxonomy of the Web's false information ecosystem, and comprise various types of false information, actors, and their motives. They reported a comprehensive overview of existing research on the false information ecosystem by identifying several lines of work: 1) how the public perceives false information; 2) understanding the propagation of false information; 3) detecting and containing false information on the Web; and 4) false information on the political stage.

In [23], the authors resorted on activity rate method and active node theory for studying rumor network topology on spreading rumor and rumor impact rate. Their model enhances and use method found in literature disease spreading model. They found that the threshold of rumor spreading can be reformatted by the mean of active node. This is done after executing mean-field method. Dynamics of rumors are analyzed and validated by numerical simulation on both homogeneous and heterogeneous network. They concluded that the network topology and node activity influence on size and transmission speed of rumors. In [24], the authors resorted on theoretical model for minimizing rumors spread. They depended on independent cascade (IC) model which is one model of influence minimization theory that operates on graphical network. Then they applied a proposed Immunization algorithm on synthetic network of data and 
results are compared using heuristic metrics.

In [25], the authors proposed a computational approach for examining the roots and spreading patterns of fake news: Evolution tree analysis. The research tries to improve the flow of quality information and combating fake news on social media depends on study of "Evolution tree analysis". The findings were; 1-Fake news was mostly generated by accounts from ordinary users, but they often included a link to noncredible news websites. 2-One important effort to minimize the impact of fake news such as literacy education, bot control, and fact-checking. 3-the Researchers have identified more than 100 websites that create and promote fake stories regularly (Shao, Ciampaglia, Flammini, \& Menczer, 2016). 4To combat fake news, it is essential to identify the origins and spreading patterns of fake stories on social media. 5-breadth, depth, and degree are terms of "Evolution tree analysis" study. This study observed that tweets about real and fake news showed different evolution patterns. The research should expand the focus further by examining other misinformation contexts and analyzing a larger scale dataset.

In [26] the authors concerned on prediction of people that will become a target of gun violence. This is done by considering the gun violence modeling it as an epidemic that might transfer between individual via social interaction. They treat the diffusion gunshot violence as an epidemiological process that propagates on social networks. They incorporate social contagion model with a predictive model for modeling this social media epidemic. They argued that, although the wide use of spatial approaches to discuss this problem and interpersonal relationship related to gang activity and drugs as the reason behind the gun shot, but the statistical models can conceptualize the violence and capture it transmitting between neighborhoods which could be caught.

In [27], the authors present a dynamic behavior analysis via structured rank minimization. They tried to learn the dynamic human behavior under real-world conditions by employing structured rank minimization. A robustness and effectiveness results of this approach was developed to outperform dynamic behavior analysis to tasks such as (i) conflict intensity prediction, (ii) prediction of valence and arousal, and (iii) tracklet matching. A framework for dynamic behavior analysis in real-world conditions was developed in this paper. It employs a novel structured rank minimization method to learn a low-complexity system from time-varying data.

In [28], the authors present a human behavior classification using local field potential (LFP) signals. It just experiments to present a human behavior classification using local field potential (LFP) signals recorded from sub-thalamic nuclei (STN). Using all LFPs with the proposed hierarchical approach improves the classification performance. Moreover, the synchronization-based method reduces the computational burden considerably while the classification performance remains relatively unchanged. The LFPs signals contain useful information for recognizing human behavior. This can be a precursor for designing the next generation of closedloop DBS systems.

In [29], the authors used varied set of social media ground truth data from Facebook, Twitter and YouTube to perform a comparative analysis of computational personality recognition methods with the aid of Big Five or Five Factor personality model. Given that this model embraces five traits: Openness, Conscientiousness, Extroversion, Agreeableness, and Emotional Stability Knowledge of an individual's personality. This model enables understanding and classifying personality to make useful predictions about interests and user behaviors across social media so that it can improve and used in recommender systems.

In [30], the authors built a system to capture user behavior that defines clusters of similar users using a similarity graph (nodes and weighted edges). The system examines the click streams similarity between users using metrics to build similarity graphs capturing user's behavioral patterns. They resorted on hierarchical clustering approach to define the most strong

In [31], the authors introduce a generic computational model for capturing the dynamics in social networking. This is done using the contagion principle with the incorporation of continuous time dimension to model the dynamics. Also, this study explores the combination of three models for social network evolution that help in analyzing and predicting human behavior in social situations. The three models are: 1) The contagion principle which tells that person's opinion, beliefs or emotions will be transmitted to a large extend as this person interacts with others. 2) The homophily principle state that, the opinions or beliefs or emotions similarity of persons' states affects the strength of the connection between them. 3) The "more becomes more" principle is the phenomenon that if someone is popular then he will become more popular as time goes by.

The following table summarizes the pros and cons of the previous work which were explained in this section.

Table 1. Pros and cons of related work

\begin{tabular}{|c|c|c|}
\hline Ref. & Pros. & Cons. \\
\hline [15] & $\begin{array}{l}\text { Studying human behavior } \\
\text { is attended and reasons } \\
\text { behind misinformation } \\
\text { spreads are studied for } \\
\text { effective psychological } \\
\text { feature. }\end{array}$ & $\begin{array}{l}\text { Proposed solutions are not } \\
\text { automated. }\end{array}$ \\
\hline $\begin{array}{l}{[16,} \\
17]\end{array}$ & $\begin{array}{l}\text { Resorted on theoretical } \\
\text { linguistics computation, } \\
\text { measurements, and } \\
\text { automating factuality } \\
\text { judgments. }\end{array}$ & $\begin{array}{l}\text { Ignoring dynamics and } \\
\text { syntactic constructions } \\
\text { behind phrases as well as } \\
\text { evaluation measurements } \\
\text { aren't satisfied. }\end{array}$ \\
\hline [18] & $\begin{array}{l}\text { They use an unsupervised } \\
\text { technique for clustering } \\
\text { users enquiring. }\end{array}$ & $\begin{array}{l}\text { Tool introduces cannot } \\
\text { assess rumor veracity and } \\
\text { the process used aren't } \\
\text { fully automated. }\end{array}$ \\
\hline [19] & $\begin{array}{l}\text { Choosing features done } \\
\text { in a systematic way and } \\
\text { rumors are detected in } \\
\text { real time post-disaster } \\
\text { situations. }\end{array}$ & $\begin{array}{l}\text { No generality in events, } \\
\text { the model tested on one } \\
\text { crisis type. }\end{array}$ \\
\hline [20] & $\begin{array}{l}\text { Newly-created dataset } \\
\text { with new truth levels is } \\
\text { built and using } \\
\text { psychological theories } \\
\text { and social science for } \\
\text { features extraction. }\end{array}$ & $\begin{array}{l}\text { Disappearance of practical } \\
\text { experiments and } \\
\text { implementation steps as } \\
\text { well as cannot capture the } \\
\text { changing characteristics of } \\
\text { rumor. }\end{array}$ \\
\hline [21] & $\begin{array}{l}\text { Hybrid model of three } \\
\text { machine learning } \\
\text { techniques is built for } \\
\text { best result and Arabic }\end{array}$ & $\begin{array}{c}\text { Neither the chosen } \\
\text { features are enough nor } \\
\text { done in a systematic way } \\
\text { and human attitudes are }\end{array}$ \\
\hline
\end{tabular}




\begin{tabular}{|c|c|c|}
\hline & language is targeted. & neglected. \\
\hline [22] & $\begin{array}{l}\text { Fulfill method presented } \\
\text { for identifying false } \\
\text { information dynamics as } \\
\text { propagation, detection, } \\
\text { user perception, and } \\
\text { containment. }\end{array}$ & $\begin{array}{l}\text { No considerations for the } \\
\text { psychological side and } \\
\text { human behavior action on } \\
\text { the study taxonomy that } \\
\text { presented. }\end{array}$ \\
\hline [24] & $\begin{array}{l}\text { The use of effective } \\
\text { scalable algorithms and } \\
\text { technique to limit } \\
\text { influence cascade overs } \\
\text { social networks. }\end{array}$ & $\begin{array}{l}\text { Rumors time propagation } \\
\text { factor is ignored and the } \\
\text { reasons behind nodes } \\
\text { influences are not taken. }\end{array}$ \\
\hline [25] & $\begin{array}{l}\text { Critical elements (origin, } \\
\text { time, hierarchy...) for } \\
\text { information spread over } \\
\text { social media are } \\
\text { considered. }\end{array}$ & $\begin{array}{l}\text { Accurate results are not } \\
\text { found as well as linguistic } \\
\text { perspectives aren't } \\
\text { exploited in studying } \\
\text { information sharing and } \\
\text { the absences of generality }\end{array}$ \\
\hline [26] & $\begin{array}{l}\text { Using contagion theory } \\
\text { for human behavior } \\
\text { detection of tendencies } \\
\text { side. }\end{array}$ & $\begin{array}{l}\text { Individual data collected } \\
\text { are being lacked in many } \\
\text { features. Depending only } \\
\text { on a single behavioral tie } \\
\text { and co-offending. }\end{array}$ \\
\hline [27] & $\begin{array}{l}\text { Automatic analysis and } \\
\text { dynamic modeling for } \\
\text { human behavior are } \\
\text { introduced and the data } \\
\text { set used includes } \\
\text { different fields, context, } \\
\text { interaction scenarios and } \\
\text { recording conditions. }\end{array}$ & $\begin{array}{l}\text { Psychological information } \\
\text { behind human are ignored. }\end{array}$ \\
\hline [28] & $\begin{array}{l}\text { Human brain signals by } \\
\text { deep brain stimulation } \\
\text { (DBS) systems are } \\
\text { incorporated in } \\
\text { classification. Reality } \\
\text { manner for real time } \\
\text { behavior recognition is } \\
\text { introduced. }\end{array}$ & $\begin{array}{l}\text { Physical transmitted } \\
\text { features are accurate, but } \\
\text { changes may happen in } \\
\text { other situations for the } \\
\text { same user. }\end{array}$ \\
\hline
\end{tabular}

\begin{tabular}{|c|c|c|}
\hline [29] & $\begin{array}{l}\text { Personality types from } \\
\text { contents are introduced } \\
\text { with multivariate } \\
\text { regression techniques. } \\
\text { Exploiting large amount } \\
\text { of linguistic and } \\
\text { emotional features. }\end{array}$ & $\begin{array}{l}\text { Model expansions from } \\
\text { another source with the } \\
\text { training example, are not } \\
\text { satisfied. }\end{array}$ \\
\hline [30] & $\begin{array}{c}\text { Applying an } \\
\text { unsupervised learning } \\
\text { technique, for automatic } \\
\text { learning human behavior } \\
\text { model from trusted } \\
\text { navigation click path } \\
\text { dataset. }\end{array}$ & $\begin{array}{c}\text { Depend only on } \\
\text { navigation path is not } \\
\text { inadequate for predicting } \\
\text { human behavior. }\end{array}$ \\
\hline [31] & $\begin{array}{c}\text { Integrating three } \\
\text { computational models, } \\
\text { concerned on dynamics } \\
\text { over time by human } \\
\text { actions. }\end{array}$ & $\begin{array}{l}\text { Absence of optimization } \\
\text { algorithms for the } \\
\text { complexity measurements } \\
\text { of presenting a hybrid } \\
\text { computational model. }\end{array}$ \\
\hline
\end{tabular}

\section{RUMORS ATTRIBUTES EXTRACTION}

Generally, it was found that most scholars relay on models' structure that are constructed from two phases: training methods and attributes engineering method as shown in figure1. Training method is done by different techniques such as natural language processing, supervised classification or hybridization between two or more methods. The second phase is the attribute engineering process that is the essential and a basic stage in the overall issue. Attributes may take many forms and can be expressed by many shapes; however, this research proposed an integrated fulfill list of attributes categorized by domains. This list is presented in table 2 which it is believed that it is the most powerful attribute that will be applicable for rumor dynamical changeable form.

\section{PROPOSED FRAMEWORK}

This research proposes an innovative idea to present a framework for dealing with rumors dynamical form and human behavior reaction on them. Studying human behavior towards rumor is done by exploiting all possible and available attributes that will give the accurate results. A flowchart is presented in figure 2 to express the idea of the research, noted that rumors attributes are stated in table 2 . 


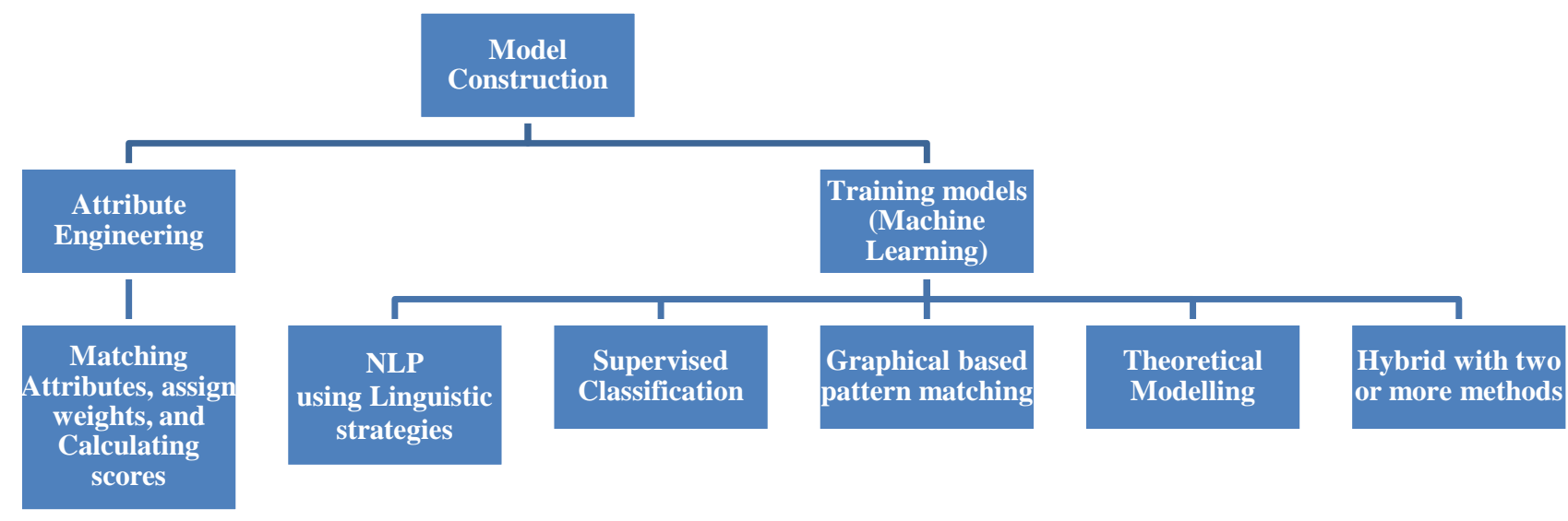

Fig 1: Techniques used in models' construction

Table 2. Rumor Attributes

\begin{tabular}{|c|c|c|c|c|}
\hline \multicolumn{2}{|c|}{ Attributes } & Sub Attributes & $\begin{array}{l}\text { Models and } \\
\text { algorithms }\end{array}$ & Ref. \\
\hline 1 & Language & $\begin{array}{c}\text { - Accent } \\
\text { - Formatters } \\
\text { - Location } \\
\text { • NLP } \\
\text { (Analysis, } \\
\text { Semantics, } \\
\text { Vectorization) }\end{array}$ & $\begin{array}{c}\text { NLP } \\
\text { algorithms }\end{array}$ & {$\left[\begin{array}{l}{[32],} \\
{[33]}\end{array}\right.$} \\
\hline 2 & Scope & $\begin{array}{l}\text { Category and } \\
\text { Dynamics }\end{array}$ & & \\
\hline 3 & Propagation & $\begin{array}{c}\text { • Diffusion } \\
\text { Influence (Source, } \\
\text { Audience, } \\
\text { Interactions, Time) } \\
\text { - Chain-Reaction } \\
\text { (path \& temporal } \\
\text { properties, Model, } \\
\text { Nodes) } \\
\text { - Spreading (Speed, } \\
\text { Direction) }\end{array}$ & $\begin{array}{c}\text { SIR model } \\
\text { Tipping } \\
\text { Model } \\
\\
\text { Independent } \\
\text { Cascade } \\
\text { Model } \\
\\
\text { Linear }\end{array}$ & $\begin{array}{l}{[34],} \\
{[35],} \\
{[36],} \\
{[37],} \\
{[38]}\end{array}$ \\
\hline 4 & Range & $\begin{array}{c}\bullet \text { Model (open, } \\
\text { closed, bounded) } \\
\bullet \text { Diameter } \\
\text { (Expansion } \\
\text { distance) } \\
\text { - Domain (Time, } \\
\text { Scope) }\end{array}$ & $\begin{array}{l}\text { Threshold } \\
\text { Model } \\
\\
\text { SpikeM } \\
\text { time-series } \\
\text { ir } \quad \mathrm{Pa}\end{array}$ & \\
\hline 5 & Sentiment & $\begin{array}{c}\text { - Polarity (Positive, } \\
\text { Negative, } \\
\text { Neutral) }\end{array}$ & $\begin{array}{c}\text { NLP } \\
\text { algorithms }\end{array}$ & $\begin{array}{l}{[39],} \\
{[40],} \\
{[41],}\end{array}$ \\
\hline
\end{tabular}

\begin{tabular}{|c|c|c|c|c|}
\hline & & $\begin{array}{c}\text { - Biasing \& } \\
\text { Tagging }\end{array}$ & & $\begin{array}{l}{[42],} \\
{[43],} \\
{[44]}\end{array}$ \\
\hline 6 & Personality & $\begin{array}{c}- \text { Traits (Big five) } \\
\bullet \text { Social Proofs } \\
\text { (Matching) }\end{array}$ & $\begin{array}{c}\text { Classificatio } \\
\mathrm{n} \\
\text { Algorithm }\end{array}$ & $\begin{array}{l}{[45],} \\
{[46]}\end{array}$ \\
\hline 9 & Impact & $\begin{array}{c}\text { - Sentiment } \\
\text { (Analysis) } \\
\text { - Social proofs } \\
\text { (Effect, Stimuli) } \\
\text { - Propagation } \\
\text { (Time-interval) } \\
\text { - Social } \\
\text { (Interaction, } \\
\text { Reaction) }\end{array}$ & $\begin{array}{l}\text { The } \\
\text { Independent } \\
\text { Cascade } \\
\text { (IC) Model } \\
\\
\text { Time-aware } \\
\text { Diffusion } \\
\text { Models } \\
\\
\text { In-degree } \\
\text { Centrality, } \\
\text { Eigenvector } \\
\text { Centrality }\end{array}$ & $\begin{array}{l}{[36],} \\
{[38],} \\
{[41],} \\
{[43],} \\
{[44]} \\
{[47]} \\
{[48],}\end{array}$ \\
\hline 7 & Behavior & $\begin{array}{l}\text { - Users meta data } \\
\text { (Language, } \\
\text { Location, Account } \\
\text { creation time) } \\
\text { - Social actions } \\
\text { (Interaction, } \\
\text { reaction, Effects) } \\
\text { - Temporal } \\
\text { similarity (Online } \\
\text { acting patterns) }\end{array}$ & $\begin{array}{c}\text { Machine } \\
\text { Learning } \\
\text { algorithms }\end{array}$ & $\begin{array}{l}{[32],} \\
{[41],} \\
{[44]} \\
{[49],} \\
{[50],} \\
{[51]}\end{array}$ \\
\hline 8 & Crowd & $\begin{array}{c}\text { - Mass (control) } \\
\text { - Purpose } \\
\text { (Analysis) } \\
\text { - Social Proof }\end{array}$ & & \\
\hline
\end{tabular}




\begin{tabular}{|c|c|c|c|c|}
\hline & & (Preferences) & & \\
\hline 10 & Broadcasting & $\begin{array}{c}\text { • Distribution } \\
\text { (Temporal } \\
\text { Similarity, Path, } \\
\text { Network) } \\
\text { • Nodes } \\
\text { (Transmitter, } \\
\text { Receivers) } \\
\text { • Channels } \\
\text { (Campaigns, } \\
\text { Bots-like signature } \\
\text { or Human-like } \\
\text { signature) }\end{array}$ & $\begin{array}{l}\text { The } \\
\text { Independent } \\
\text { Cascade } \\
\text { (IC) Model } \\
\\
\text { The Linear } \\
\text { Threshold } \\
\text { (LT) Model } \\
\\
\text { Time-aware } \\
\text { Diffusion } \\
\text { Models }\end{array}$ & $\begin{array}{l}{[44],} \\
{[52],} \\
{[53]}\end{array}$ \\
\hline 11 & Graph & $\begin{array}{c}\text { - Social (Relation, } \\
\text { Interaction) } \\
\text { - Nodes (Type, } \\
\text { Mode) } \\
\text { - Edges (Path, } \\
\text { Flow, Grouping) } \\
\text { - Network (Flow, } \\
\text { Polymerization) }\end{array}$ & $\begin{array}{l}\text { Push and } \\
\text { pull strategy } \\
\text { Independent } \\
\text { Cascade } \\
\text { (IC) Model } \\
\\
\text { Linear } \\
\text { Threshold } \\
\text { (LT) Model. } \\
\text { In-degree, } \\
\text { Eigenvector } \\
\text { Centrality }\end{array}$ & $\begin{array}{l}{[36],} \\
{[37],} \\
{[44],} \\
{[47],} \\
{[48],} \\
{[53]}\end{array}$ \\
\hline
\end{tabular}

The flowchart will execute as following:

1. After initiation and stratifications, data such social graphs, sender nodes, nodes metadata, demographic data, keywords, and events time is collected by choosing an appropriate API and inputted in the system.

2. First phase: in the first phase the gathered data must be prepared and preprocessed to be transferred into suitable form for further processing.

3. Preprocessing is first done by filtering and analyzing data. Data are cleaned and filtered by removing noise, redundant and inconsistent data.

4. Then, classifying data according to similar clusters with a single format and one data source.

5. Then, data is wrapping and transformed by adding certain labels and attributes, aggregating, normalizing, labelling and framing it.

6. Second phase is processing the prepared data by monitoring, finding, and extracting attributes corresponding to each data frames.

7. Assign appropriate weight for each extracted attribute.

8. Find and calculate formulas assigned for each data attributes extracted from previous step and get the result scores.

9. For each calculated attribute formula, range the calculated scores for identifying the level of veracity.

10. Integrate all the calculated ranged scores, and sum up each for obtaining the overall global score.

11. Print the result reports.

12. Put rules and thresholds for taking the decision on approving the data to be rumor or not.

\section{CONCLUSION}

This paper presents an innovative idea in steps that may help to build an integrated framework for rumors confrontation. A full survey has been made in recent techniques and computational models of rumors and human behavior field with a proposed advantages and disadvantages for each. It was found that the processes of human behavior detection and rumor identification cannot be split as both processes affect each other directly or indirectly. Also, it was found that rumor detection frameworks are constructed by supervised machine learning techniques learned from manual labeled data and a defined list of attributes, which have deficiencies need to be improved. Number of recommendations are proposed such as a list of 11 domain attributes, each are stated with number of sub-attributes for describing and calculating them accurately. As well as, a proposed framework is given and presented in flowchart for calculating formulas and scores that can range and assess data depending on above recommended attributes and sub-attributes. The framework skeleton is presented in which it may arrange ideas, express general steps and help in constructing integrated executable system for deterring rumors.

\section{FUTURE WORK}

The proposed framework is willing to be turned into the practical environment and enter the real world. 


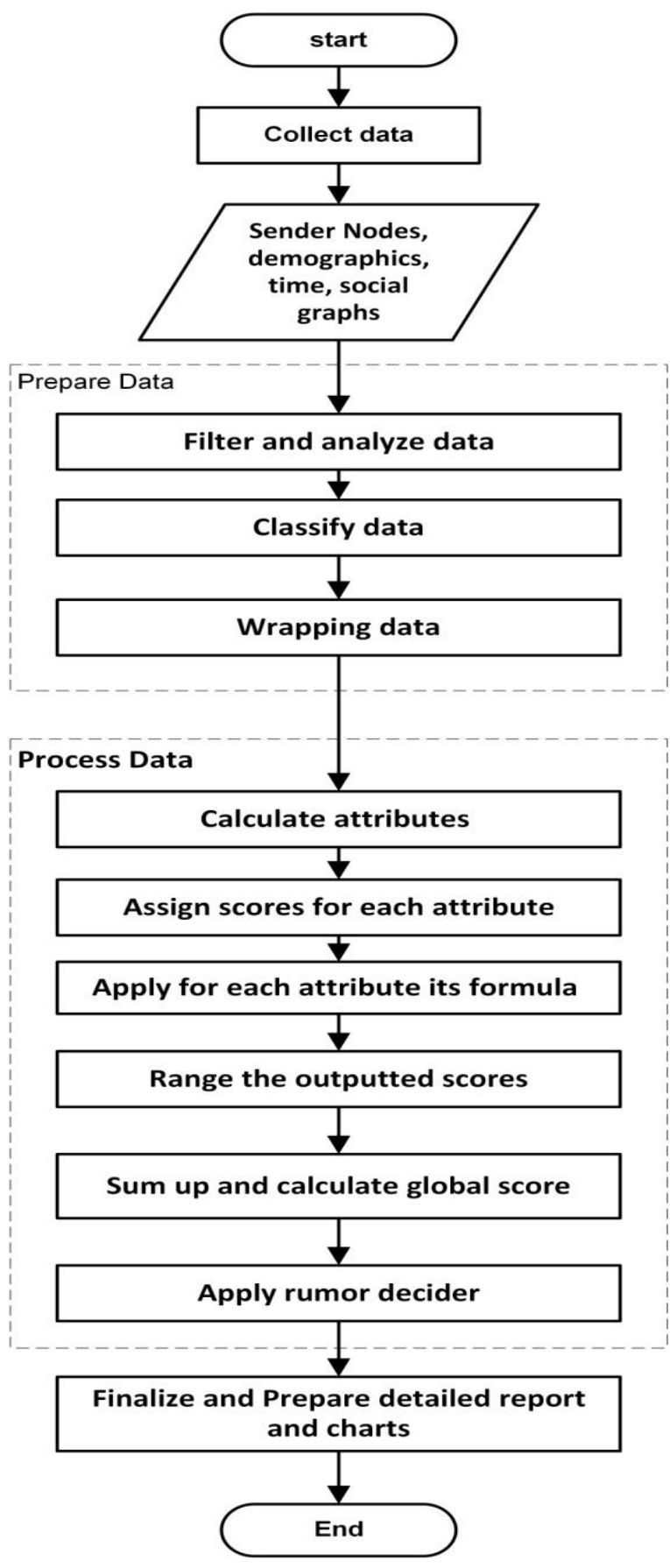

Fig 2: Proposed Framework

Executing it and putting it into practical work is the first target, as well as applying experiments and testing phases. Also, it is planned to consider the detection of rumor origin. This issue is a challenge as it is difficult to find the users who started the rumor and their intentions. This issue reveals another challenge point, that is the detection of new rumors in real-time stage. It is a complicated process to detect rumor before its spread as well as knowing the causer in real-time stage is a big deal.

\section{REFERENCES}

[1] Han, B. and Srinivasan, A., 2012, June. Your friends have more friends than you do: identifying influential mobile users through random walks. In Proceedings of the thirteenth ACM international symposium on Mobile Ad Hoc Networking and Computing (pp. 5-14). ACM.
[2] Halse, S.E., Tapia, A.H., Squicciarini, A.C. and Caragea, C., 2016, May. Tweet Factors Influencing Trust and Usefulness During Both Man-Made and Natural Disasters. In ISCRAM.

[3] Liu, F., Burton-Jones, A. and Xu, D., 2014, January. Rumors on Social Media in disasters: Extending Transmission to Retransmission. In PACIS (p. 49).

[4] Huang, Y.L., Starbird, K., Orand, M., Stanek, S.A. and Pedersen, H.T., 2015, February. Connected through crisis: Emotional proximity and the spread of misinformation online. (pp. 969-980). ACM.

[5] Wang, Z., Tu, L., Guo, Z., Yang, L.T. and Huang, B., 2014. Analysis of user behaviors by mining large network data sets. Future Generation Computer Systems, 37, pp.429-437.

[6] Renso, C., Baglioni, M., de Macedo, J.A.F., Trasarti, R. and Wachowicz, M., 2013. How you move reveals who you are: understanding human behavior by analyzing trajectory data. Knowledge and information systems, 37(2), pp.331-362.

[7] Zhao, L., Yin, J. and Song, Y., 2016. An exploration of rumor combating behavior on social media in the context of social crises. Computers in Human Behavior, 58, pp.25-36.

[8] Coviello, L., Sohn, Y., Kramer, A.D., Marlow, C., Franceschetti, M., Christakis, N.A. and Fowler, J.H., 2014. Detecting emotional contagion in massive social networks. PloS one, 9(3), p.e90315.

[9] Oh, O., Agrawal, M. and Rao, H.R., 2013. Community intelligence and social media services: A rumor theoretic analysis of tweets during social crises. Mis Quarterly, pp.407-426

[10] DiFonzo, N. and Bordia, P., 2007. Rumor psychology: Social and organizational approaches (Vol. 750). Washington, DC: American Psychological Association

[11] Allport, G.W. and Postman, L., 1947. The psychology of rumor.

[12] Friggeri, A., Adamic, L., Eckles, D. and Cheng, J., 2014, May. Rumor cascades. In Eighth International AAAI Conference on Weblogs and Social Media.

[13] Jin, Z., Cao, J., Guo, H., Zhang, Y., Wang, Y. and Luo, J., 2017, July. Detection and analysis of 2016 us presidential election related rumors on twitter. In International conference on social computing, behavioral-cultural modeling and prediction and behavior representation in modeling and simulation (pp. 14-24). Springer, Cham

[14] Alexander, D.E., 2014. Social media in disaster risk reduction and crisis management. Science and engineering ethics, 20(3), pp.717-733

[15] Chen, X., Sin, S.C.J., Theng, Y.L. and Lee, C.S., 2015, June. Why do social media users share misinformation? In Proceedings of the 15th ACM/IEEE-CS Joint Conference on Digital Libraries (pp. 111-114). ACM.

[16] Mitra, T., Wright, G.P. and Gilbert, E., 2017, February. A parsimonious language model of social media credibility across disparate events. In Proceedings of the 2017 ACM Conference on Computer Supported Cooperative Work and Social Computing (pp. 126-145). 
ACM.

[17] Mitra, T. and Gilbert, E., 2015, April. Credbank: A largescale social media corpus with associated credibility annotations. In Ninth International AAAI Conference on Web and Social Media.

[18] Zhao, Z., Resnick, P. and Mei, Q., 2015, May. Enquiring minds: Early detection of rumors in social media from enquiry posts. In Proceedings of the 24th International Conference on World Wide Web (pp. 1395-1405). International World Wide Web Conferences Steering Committee.

[19] Mondal, T., Pramanik, P., Bhattacharya, I., Boral, N. and Ghosh, S., 2018. Analysis and early detection of rumors in a post disaster scenario. Information Systems Frontiers, 20(5), pp.961-979.

[20] Dang, A., Moh'd, A., Islam, A. and Milios, E., 2019, January. Early Detection of Rumor Veracity in Social Media. In Proceedings of the 52nd Hawaii International Conference on System Sciences.

[21] Sabbeh, S.F. And Baatwah, S.Y., 2018. Arabic News Credibility On Twitter: An Enhanced Model Using Hybrid Features. Journal Of Theoretical \& Applied Information Technology, 96(8).

[22] Zannettou, S., Sirivianos, M., Blackburn, J. and Kourtellis, N., 2019. The web of false information: Rumors, fake news, hoaxes, clickbait, and various other shenanigans. Journal of Data and Information Quality (JDIQ), 11(3), p.10.

[23] Huo, L.A., Ding, F., Liu, C. and Cheng, Y., 2018. Dynamical Analysis of Rumor Spreading Model considering Node Activity in Complex Networks. Complexity, 2018.

[24] Ibrahim, R.A., Hefny, H.A. and Hassanien, A.E., 2016, October. Controlling Rumor Cascade over Social Networks. In International Conference on Advanced Intelligent Systems and Informatics (pp. 456-466). Springer, Cham.

[25] Jang, S.M., Geng, T., Li, J.Y.Q., Xia, R., Huang, C.T., Kim, H. and Tang, J., 2018. A computational approach for examining the roots and spreading patterns of fake news: Evolution tree analysis. Computers in Human Behavior, 84, pp.103-113.

[26] Green, B., Horel, T. and Papachristos, A.V., 2017. Modeling contagion through social networks to explain and predict gunshot violence in Chicago, 2006 to 2014. JAMA internal medicine, 177(3), pp.326-333.

[27] Georgakis, C., Panagakis, Y. and Pantic, M., 2018. Dynamic behavior analysis via structured rank minimization. International journal of computer vision, 126(2-4), pp.333-357.

[28] Golshan, H.M., Hebb, A.O., Hanrahan, S.J., Nedrud, J. and Mahoor, M.H., 2018. A hierarchical structure for human behavior classification using STN local field potentials. Journal of neuroscience methods, 293, pp.254-263.

[29] Farnadi, G., Sitaraman, G., Sushmita, S., Celli, F., Kosinski, M., Stillwell, D., Davalos, S., Moens, M.F. and De Cock, M., 2016. Computational personality recognition in social media. User modeling and user- adapted interaction, 26(2-3), pp.109-142.

[30] Wang, G., Zhang, X., Tang, S., Zheng, H. and Zhao, B.Y., 2016, May. Unsupervised clickstream clustering for user behavior analysis. In Proceedings of the 2016 CHI Conference on Human Factors in Computing Systems (pp. 225-236). ACM.

[31] Blankendaal, R., Parinussa, S. and Treur, J., 2016, August. A Temporal-Causal Modelling Approach to Integrated Contagion and Network Change in Social Networks. In ECAI (pp. 1388-1396).

[32] Zubiaga, A., Liakata, M. and Procter, R., 2017, September. Exploiting context for rumour detection in social media. In International Conference on Social Informatics (pp. 109-123). Springer, Cham.

[33] Tolosi, L., Tagarev, A. and Georgiev, G., 2016, April. An analysis of event-agnostic features for rumour classification in twitter. In Tenth International AAAI Conference on Web and Social Media.

[34] Liu, Y., Zeng, C. and Luo, Y., 2018. Dynamics of a New Rumor Propagation Model with the Spread of Truth. Applied Mathematics, 9(05), p.536.

[35] Liu, Q., Li, T. and Sun, M., 2017. The analysis of an SEIR rumor propagation model on heterogeneous network. Physica A: Statistical Mechanics and its Applications, 469, pp.372-380.

[36] Ma, J., Gao, W. and Wong, K.F., 2017, July. Detect rumors in microblog posts using propagation structure via kernel learning (pp. 708-717)

[37] Conti, M., Lain, D., Lazzeretti, R., Lovisotto, G. and Quattrociocchi, W., 2017, December. It's always April fools' day: On the difficulty of social network misinformation classification via propagation features. (pp. 1-6). IEEE.

[38] Zhu, L., Zhao, H. and Wang, H., 2016. Complex dynamic behavior of a rumor propagation model with spatial-temporal diffusion terms. Information Sciences, 349, pp.119-136.

[39] Zeng, L., Starbird, K. and Spiro, E.S., 2016, January. Rumors at the speed of light? Modeling the rate of rumor transmission during crisis. In 2016 49th Hawaii International Conference on System Sciences (HICSS) (pp. 1969-1978). IEEE.

[40] Zeng, L., Starbird, K. and Spiro, E.S., 2016, March. \# unconfirmed: Classifying rumor stance in crisis-related social media messages. In Tenth International AAAI Conference on Web and Social Media.

[41] Hamidian, S. and Diab, M., 2016, June. Rumor identification and belief investigation on twitter. In Proceedings of the 7th Workshop on Computational Approaches to Subjectivity, Sentiment and Social Media Analysis (pp. 3-8).

[42] Beigi, G., Hu, X., Maciejewski, R. and Liu, H., 2016. An overview of sentiment analysis in social media and its applications in disaster relief. In Sentiment analysis and ontology engineering (pp. 313-340). Springer, Cham.

[43] Kwon, K.H., Bang, C.C., Egnoto, M. and Raghav Rao, H., 2016. Social media rumors as improvised public opinion: semantic network analyses of twitter discourses during Korean saber rattling 2013. 
[44] Ferrara, E., Varol, O., Davis, C., Menczer, F. and Flammini, A., 2016. The rise of social bots. Communications of the ACM, 59(7).

[45] Bessi, A., 2016. Personality traits and echo chambers on facebook. Computers in Human Behavior, 65, pp.319324.

[46] Shu, K., Wang, S. and Liu, H., 2018, April. Understanding user profiles on social media for fake news detection. In 2018 IEEE Conference on Multimedia Information Processing and Retrieval (MIPR) (pp. 430435). IEEE.

[47] Li, Y., Fan, J., Wang, Y. and Tan, K.L., 2018. Influence maximization on social graphs: A survey. IEEE Transactions on Knowledge and Data Engineering, 30(10), pp.1852-1872.

[48] Liu, Y., Jin, X., Shen, H. and Cheng, X., 2017, May. Do rumors diffuse differently from non-rumors? A systematically empirical analysis in Sina Weibo for rumor identification. (pp. 407-420). Springer, Cham.

[49] Arif, A., Shanahan, K., Chou, F.J., Dosouto, Y., Starbird, K. and Spiro, E.S., 2016, February. How information snowballs: Exploring the role of exposure in online rumor propagation. In Proceedings of the 19th ACM Conference on Computer-Supported Cooperative Work \& Social Computing (pp. 466-477). ACM.

[50] Zubiaga, A., Liakata, M., Procter, R., Hoi, G.W.S. and Tolmie, P., 2016. Analysing how people orient to and spread rumours in social media by looking at conversational threads. PloS one, 11(3)

[51] Chen, W., Yeo, C.K., Lau, C.T. and Lee, B.S., 2016, October. Behavior deviation: An anomaly detection view of rumor preemption. In 2016 IEEE 7th Annual Information Technology, Electronics and Mobile Communication Conference (IEMCON) (pp. 1-7). IEEE.

[52] Varol, O., Ferrara, E., Menczer, F. and Flammini, A. 2017. Early detection of promoted campaigns on social media. EPJ Data Science, 6(1), p.13.

[53] Louni, A. and Subbalakshmi, K.P., 2018. Who spread that rumor: Finding the source of information in large online social networks with probabilistically varying internode relationship strengths. IEEE Transactions on Computational Social Systems, 5(2), pp.335-343. 